DOI: https://doi.org/10.24127/ajpm.v10i4.4254

\title{
EKSPLORASI ETNOMATEMATIKA SEBAGAI SUMBER BELAJAR MATEMATIKA DI KABUPATEN ENDE
}

\author{
Yasinta Yenita Dhiki ${ }^{1 *}$, Maria Goretty D. Bantas ${ }^{2}$ \\ ${ }^{1,2}$ Universitas Flores, Ende, Nusa Tenggara Timur, Indonesia \\ ${ }^{*}$ Corresponding author. \\ E-mail: $\quad$ dhikiyasinta@gmail.com $^{1 *}$ \\ gorettybantas@gmail.com $^{2)}$
}

Received 10 September 2021; Received in revised form 04 December 2021; Accepted 28 December 2021

\begin{abstract}
Abstrak
Pendidikan dan budaya adalah sesuatu yang tidak dapat dipisahkan dalam kehidupan sehari-hari. Etnomatematika hadir untuk menjembatani antara budaya dan pendidikan khususnya dalam pembelajaran matematika.Tanpa disadari masyarakat telah melakukan berbagai aktivitas dengan meggunakan konsep dasar matematika dan ide-ide matematis.Penelitian ini bertujuan untuk mengkaji dan menganalisis eksplorasi etnomatematika budaya dan adat istiadat kabupaten Ende agar diperoleh informasi dasar dalam pengembangan ilmu etnomatematika terhadap pembelajaran matematika. Penelitian ini merupahkan penelitian Deskriptif Kualitatif, menggunakan metode studi lapangan, wawancara dan studi dokumen. Analisis data yang digunakan adalah analisis model Miles and Huberman. Aktivitas dalam analisis data yaitu data reduction, data display, dan conclusion drawing/verification.Berdasarkan kajian terhadap budaya Ende di peroleh beberapa unsur Etnomatematika di antaranya geometri bidang, Geometri Ruang, pola bilangan dan satuan berat.Penelitian sebenarnya masih belum mendalami, di sarankan bagi peneliti lanjutan agar di galih lebih mendalam terkait sruktur, filosofis dalam kehidupan masyarakat Kabupaten Ende.
\end{abstract}

Kata kunci: Eksplorasi; etnomatematika; sumber belajar.

\begin{abstract}
Education and culture are something that cannot be separated in everyday life. Ethnomathematics is here to bridge between culture and education, especially in learning mathematics. Without realizing it, the community has carried out various activities using basic mathematical concepts and mathematical ideas. This study aims to study and analyze the ethnomathematical exploration of the culture and customs of Ende district in order to obtain basic information in the development of ethnomathematical science towards learning mathematics. This research is a qualitative descriptive research, using the methods of field studies, interviews and document studies. Analysis of the data used is the analysis of the Miles and Huberman model. Activities in data analysis are data reduction, data display, and conclusion drawing/verification. further researchers to explore more deeply related to structure, philosophy in the life of the people of Ende Regency.
\end{abstract}

Keywords: Ethnomathematics; exploration; learning resources.

This is an open access article under the Creative Commons Attribution 4.0 International License

\section{PENDAHULUAN}

Manusia tanpa kebudayaan dan pendidikan bagaikan kesatuan tubuh yang tanpa arti. Karena kebudayaan, manusia dapat mengetahui semua yang ada di lingkungannya. Peranan kebudayaan dan pendidikan sangat penting bagi kehidupan manusia.Sekolah adalah salah satu contoh kebudayaan dan pendidikan. Sekolah merupakan suatu lembaga utama (selain keluarga) yang dipergunakan oleh orang dewasa dalam mewariskan kebudayaan kepada anakanaknya (generasi penerus). Oleh karena itu orang dewasa yang ada di sekolah (guru) harus memiliki pemaha- 
man yang jelas tentang budaya yang berkembang di masyarakat, baik secara mikro maupun secara makro yang meliputi tentang nilai, kepercayaan, dan norma. Beberapa Tahun belakangan ini mulai banyak di kaji penelitian yang menghubungkan antara matematika dan budaya.

Berkaitan dengan peningkatan sumber daya manusia melalui bidang pendidikan, maka matematika dianggap sebagai dasar dari sebagian proses pendidikan, dimana matematika dianggap sebagai sumber dari konsep berpikir yang dapat membantu dalam pemecahan masalah yang dihadapi sehari-hari. Matematika adalah bagian dari kebudayaan masyarakat dan matematika serta pembelajaran matematika menjadikan matematika menjadi milik semua orang bahkan matematika lahir dari perjalanan hidup manusia atau disebut dengan hasil dari kebudayaan manusia. Oleh karena itu, manusia dan kebudayaan selalu memiliki ikatan (Ubayanti, Lumbantobing, \& Manurung, 2016). Secara tidak sadar aktivitas yang dilakukan setiap hari tidak terlepas dengan matematika seperti kebiasaan berbelanja dan yang lainnya. Kebiasaan yang menunjukkan budaya masyarakat setempat jika dikaitkan dengan matematika dikenal dengan istilah etnomatematika. Etnomatematika merupakan matematika yang tumbuh dan berkembang dalam masyarakat tertentu.

Eratnya kaitan antara matematika dan kebudayaan atau disebut etnomatekatika memunculkan serangkaian inovasi pembelajaran matematika dengan memanfaatkan budaya atauoun sebaliknya. Hasil kajian matematika dalam budaya kemudian diintegrasikan dalam pembelajaran matematika sebagai upaya sistematis untuk melestarikan dan mewariskan budaya (Nuryadi, 2020). Sebaliknya, pembelajaran matematika di sekolah dapat menajdi lebih bermakna jika disesuaikan dengan perkembangan kognitif peserta didik dan menggunakan konteks lingkungan sekitar peserta didik (Putra, Wijayanto, \& Widodo, 2020). Lebih lanjut, telah banyak dilakukan eksplorasi berbagai macam kebudayaan di Indonesia yang dikaitkan dengan proses belajar matematika khususnya sebagai sumber belajar ((Riski, Tito, \& Krister, 2020); (Putri, 2017); (Marina \& Izzati, 2019); (Manapa, 2021); (Sutarto, Ahyansyah, Mawaddah, \& Hastuti, 2021); dan (Rohmaini, Netriwati, Komarudin, Nendra, \& Qiftiyah, 2020).

Salah satu budaya yang sudah dieksplorasi adalah budaya suku Ende, Nusa Tenggara Timur. Eksplorasi tersebut masih dalam lingkup makna simbolik dari produk kebudayaan suku Ende (Rupa \& Ri'a, 2021). Akan tetapi, disamping itu dalam budaya kabupaten Ende terdapat beberapa symbol atau alat yang sering digunakan dalam ceremonial adat dapat juga dijadikan sebagai media atau sumber belajar dalam proses penjelasan materi matematika. Media atau sumber balajar yang dimaksud lebih kepada media grafis. Beberapa bagian dari buaya suku Ende yang secara sekilas sejalan dengan konsep matematika diantaranya ada pada bentuk rumah adat, motif tenun, bentuk gong adat dan kue cucur untuk menjelaskan materi geometri dalam matematika. Berdasarkan penjelasan tersebut, dapat disimpulkan bahwa tujuan dari penelitian ini adalah untuk mengeksplorasi atau melakukan kajian etnomatematika pada budaya suku Ende di Nusa Tenggara Timur yang dapat digunakan sebagai sumber belajar matematika. 
DOI: https://doi.org/10.24127/ajpm.v10i4.4254

\section{METODE PENELITIAN}

Penelitian ini merupahkan penelitian deskriptif kualitatif, dengan pendekatan etnografi. penelitian ini terfokus pada alat music tradisional, anyaman tradisional, pakaian adat, kue tradisional, rumah adat yang ada dalam budaya masyrakatan Ende-Lio.

Metode penelitian yang di gunakan yaitu; studi lapangan, wawancara dan studi dokumen untuk mendapatkan data yang valid. Penelitian di laksanakan di Kampung adat wolotopo di desa Wolotopo, kelopok tenun ikat Moke Keso, pengrajin anyaman, ibu-ibu yang yang memahami pembuaan kue tradisional di kelurahan Rewa Rangga Kabupaten Ende.

Instrumen penelitian melalui wawancara yang diberikan pada pemuka adat (Mosa laki), pengraji tenun ikat dan anyaman yang serta pembuatan kue tradisional yang memahami dan seluk beluk pembuatannya. Penelitian ini di awali dengan melakukan survei pada tempat penelitian, menyusun instrumen peneltian, menentukan jadwal penelitian dan pelaksanaan penelitian . pengumpulan data dilakukan dengan wawancara, studi lapangan dan dokumentasi.

Analisis data yang digunakan adalah teknik triangulasi, menggunakan model Miles and Huberman yang terdiri dari data reduction/reduksi data, data display/ penyajian data, dan conclusion drawing/verification / penarikan kesimpulan/ verifikasi. Pada langkah reduksi data peneliti mengubah data gambar kebentuk tulisan serta menyeleksi data yang tidak diperluka. Selanjutnya penyajian data dimana Hasil wawancara, studi lapangan dan studi dokumen yang ditemukan pada rumah adat, anyaman tradisional, alat music tradisional, pakaian adat, dan kue tradisional di eksplorasi untuk mendeskripsikan unsur-unsur matematika apa saja yang terdapat di dalamnya. Kemudian pearikan kesimpulan dengan memilih unsur matematika yang terdapat sebagai pembelajaran di sekolah yaitu unsur geometri bidang datar dan geometri bidang ruang, perbandingan.tahap terakhir penarikan kesimpulan.

\section{HASIL DAN PEMBAHASAN}

Hasil atau temuan dalam penelitian ini meliputi hal-hal yang menjadi bagian dari kebudayaan EndeLio yang memiliki keterkaitan dengan matematika dan dapat digunakan sebagai sumber belajar. Berikut ini disajikan hasil dari penelitian yang telah dilakukan.

\section{Feko (suling)}

Bagian dari kebudayaan suku Ende Lio yang memiliki nilai etnomatematika adalah feko atau suling. Adapun bentuk dari feko dapat dilihat pada Gambar 1.

\section{Gambar 1. Feko (suling)}

Bahan pembuatannya berasal dari bamboo wuluh (buluh)yang tipis dan dilubangi pada salah satu sisi. Di situ terdapat lubang tiupan sebesar ujung jari. Udara yang kita tiup masuk ke dalam tabung, mengalir dan membentur sepanjang dinding tabung yang berfungsi sebagai resonator. Dikenal beberapa jenis suling yang biasa 
dimainkan oleh masyarakat Ende Lio antara lain:

a. Feko jedhu/Nangi: ditiup pada saat tengah malam dengan mengalunkan nada-nada ratap dan cara meniupnya seperti rekorder.

b. Feko Bu: ditiup dengan nada-nada improvisasi solis, diiringi dengan beberapa gendang dan jenis suling ini disebut juga suling para gembala.

c. Feko Redho: jenis suling ini ditiup secara duet atau trio Pda harmonis pada nada-nada lagu, bisa digunakan untuk arak-arakan pengantin atau acara lainnya.

d. Feko Ria: jenis suling ini ditiup secara kelompok dalam paduan nada secara harmonis dalam irama mars atau irama lainnya pada acara pernikahan atau acara resmi lainnya.

e. Feko Pupu: suling ini bentuknya agak unik seperti alat pompa dan cara meniupnya dengan menggeser bamboo untuk menghasilkan nada bass. Berdasarkan hasil temua, bangun ruang dapat ditemukan pada feko.

\section{Genda (gendang)}

Selanjutnya terdapat genda atau gendang yang bentuknya dapat dilihat pada Gambar 2.

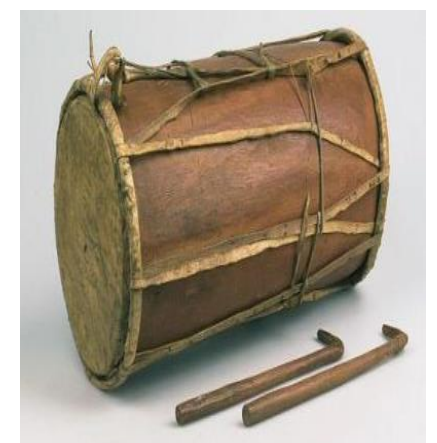

Gambar 2. Genda (gendang)

Gendang dalam bahasa Ende Lio dikenal dengan sebutan Genda/Albana. Genda/Albana tersebut dari pangkal batang kelapa dan kulit sapi atau kambing. Bentuknya bulat seperti periuk/podo pada bagian permukaannya. Dalam komposisinya ada lima buah genda atau albana yaitu:

a. Genda Redhu, ukuran kecil sebanyak dua buah untuk improvisasi.

b. Genda Wasa, ukuran sedang sebanyak dua buah untuk ritme.

c. Genda Jedhu, ukuran besar sebanyak satu buah untuk bass music genda/albana biasanya dipadukan dengan suling/feko.

\section{Kidhe}

Bentuk dari Kidhe dapat dilihat pada Gambar 3.

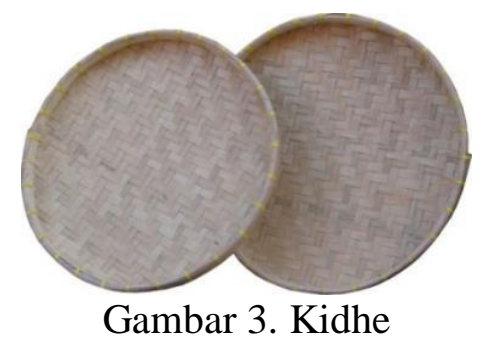

Kidhe dianyam dari kulit bambu dengan bentuk ceper dan bulat. Permukaanya dianyam dengan tali ngidho/rata dan bulatan bila bambu agar menjadi kuat. Kegunaannya untuk menapis beras/padi dan juga digunakan sebagai payung di saat hujan, berdasarkan uraian gambar di atas di simpulkan bangun datar lingkaran dapat di temukan pada anyaman tradisional Kidhe/idhe.

\section{Lawo Soke}

Bentuk dari Lawo Soke dapat dilihat pada Gambar 4. Motif Lawo Soke Mata Ria dibuat berdasarkan meniru daun sukun yang berdiri tempel pada lawo dan kata Soke artinya menancap dan Ria artinya besar. Jadi Lawo Soke Mata Ria artinya motif daun 
sukun yang besar yang dimunculkan pada sarung/lawo. Sarung ini dipakai pada saat acara keluarga dan acara adat baik yang resmi maupun tidak resmi. pada motif lawo soke, dalam matematika yaitu berbentuk bangun datar belah ketupat. Adapun jenis motif dari soke lio yang disajikan pada Gambar 4 adalah sarung perempuan. Jumlah motif vertikal sebanyak 7 motif sedangkan horizontal sebanyak $2 \times 4$ motif. Jumlah lembarnya adalah 3 dengan 2 lembar Singi dan 1 One.

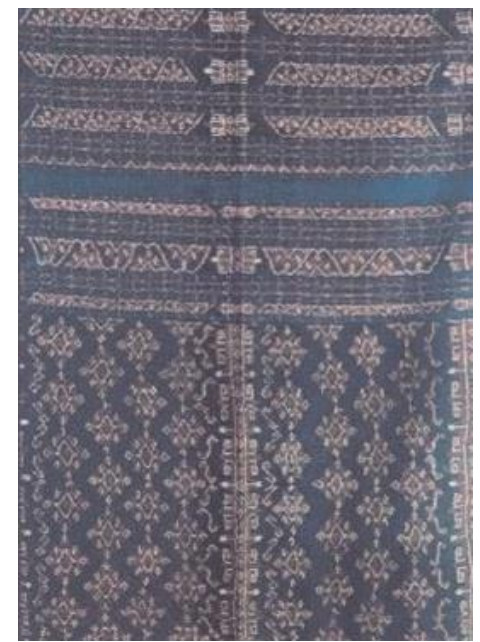

Gambar 4. Lawo soke

\section{Lawo Manu}

Lawo manu merupakan salah satu motif batik Ende. Bentuk dari Lawo manu dapat dilihat pada Gambar 5.

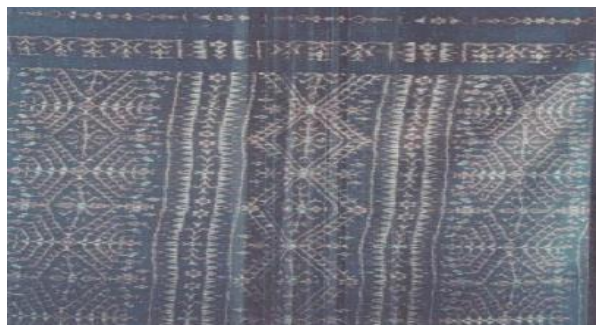

Gambar 5. Lawo manu

Motif lawo manu dibuat berdasarkan meniru seekor binatang ayam. Yang berdiri temple pada lawo dan kata manu yang artinya ayam. umlah motif : vertikal 7 motif, horizontal 2x 6 motif. Jumlah lembar : 3 lembar terdiri dari 1 one dan 2 singi. Pada motif lawo maanu, menyerupai bangun datar belah ketupat dalam matematika.

\section{Sao Musa Laki}

Sao musa laki atau rumah musalaki merupakan rumah adat masyarakat suku Ende. Bentuk dari sao musa laki dapat dilihat pada Gambar 6.

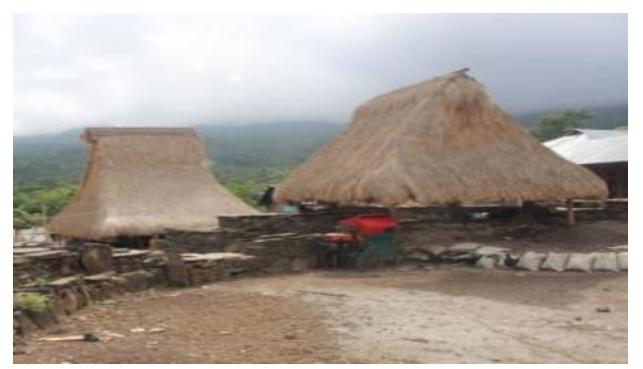

Gambar 6. Sao musa laki

Nama Musa laki diambil dari kata dalam bahasa Ende Lio yaitu mosa yang berarti ketua dan laki yang berarti adat, yang jika digabungkan artinya adalah "ketua adat" atau "kepala suku", jadi rumah Musalaki adalah rumah yang menjadi tempat tinggal bagi tetua atau kepala suku dalam masyarakat suku Ende Lio. Rumah Adat Musalaki mempunyai bentuk persegi empat dengan atap yang menjulang tinggi sebagai simbol kesatuan dengan sang pencipta. Bentuk atap tersebut diyakini menyerupai layar perahu sebagaimana cerita dalam masyarakat setempat mengenai nenek moyang Suku Ende Lio yang sudah terbiasa menggunakan perahu. Pada bagian atas atap terdapat dua ornamen yang memiliki simbol yaitu kolo Musalaki (kepala rumah keda) dan kolo ria (kepala rumah besar) di mana diyakini kedua bangunan memiliki hubungan spiritual. 
Secara arsitektir bangunan, sao musa laki dibangun oleh 2 struktur, yaitu struktur bawah dan atas. Pada struktur bagian bawah terdapat 2 struktur lagi, yaitu struktur pondasi kuwu lewa dan struktur maga (lantai). Struktur pondasi pada bangunan Sao Musalaki menggunakan bahan batu lonjong yang dipasang berdiri secara vertikal yang bermanfaat untuk menghindari kereta-kan pada kolom bangunan pada saat terjadi situasi tak terduga seperti gempa dan bencana alam lainnya, sedangkan lantai dibuat seperti panggung bertujuan untuk memungkinkan sirkulasi udara dari bawah lantai dapat berjalan baik, sehingga dapat mengatasi dan menghindari kelembapan pada lantai bangunan. Berikutnya pada struktur maga, maga terbuat dari terbuat dari bilah papan yang disusun sejajar dengan sistem satu arah. Struktur lantai pada Musalaki terdiri dari dua bagian yaitu lantai tenda teo (teras gantung) dan lantai koja ndawa (lantai ruang dalam), yang menjadi pembeda antara keduanya adalah perbedaan tinggi lantai tersebut. Tujuan pembuatan lantai dari bilah papan ini adalah agar udara yang melewati kolong rumah dapat masuk ke ruang atas, sama seperti penjelasan pada bagian pondasi sebelumnya.

Sama halnya dengan struktur bawah, struktur bagian atas juga terdiri dari 2 struktur lagi, yaitu struktur wisu dan struktur atap. Struktur wisu atau struktur atas lantai sao musa laki terdiri dari empat buah wisu penyangga yang ditopang dari isi ine wawo (balok kayu palang bagian atas) yang memiliki panjang $400 \mathrm{~cm}$ yang ditopang oleh isi mbasi (balok kayu palang bagian bawah) yang panjangnya $450 \mathrm{~cm}$. Masing-masing wisu mempunyai ciri khas ukiran yang mempunyai filosofi bagi masyarakat Suku Ende Lio.

\section{Wati}

Wati merupakan kerajinan tangan yang terbuat dari daun lontar. Bentuk dari wati dapat dilihat pada Gambar 7.

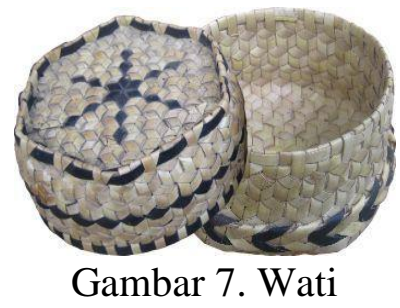

Wati dianyam dari daun lontar atau bhoka au dengan bentuk enam sudut hingga delapan sudut, dilengkapi dengan tutupannya dan gunanya untuk mengisi bekal, bibit tanaman, benang dan bahkan emas murni. Sehingga dulu ada istilah wea se wati (emas satu wati) Wati mempunyai bentuk sangat banyak dan adapula yang bermotif diantaranya wati woga, wati robha, wati wuga dan lain-lain. pada wati dapat di temukan bentuk bangun datar segi enam.

\section{Kopa}

Kopa juga merupakan hasil kerajinan tangan yang terbaut dari daun lontar atau bisa juga dari bilang bambu. Bentuk fisik dari Kopa dapat dilihat pada Gambar 8.

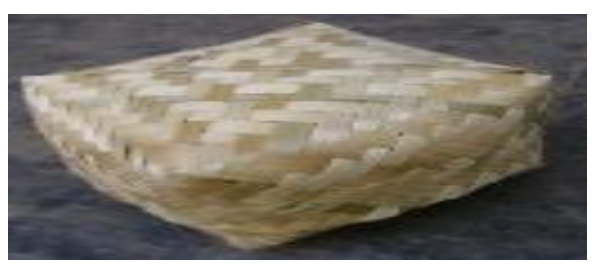

Gambar 8. Kopa

Bentuknya seperti peti, digunakan untuk menyimpan pakaian lambu, luka, lawo, dianyam dari daun lontar dan bilah bambu yang dilengkapi dengan tutupannya dan ada juga dinamakan kopa wuga. pada kopak dapat ditemukan bangun ruang kubus. 


\section{Mbeka Weti}

Mbeka weti adalah tempat sirih pinang/ kapur yang dianyam dari daun lontar dengan bentuk empat persegi, dibuat dari 2 susun dan bagian dalam dibuat laci-laci untuk menyimpan uang, pe'a bako dll. pada wati di temukan bangun ruang Balok. Bentuk dari mbeka weti dapat dilihat pada Gambar 9.

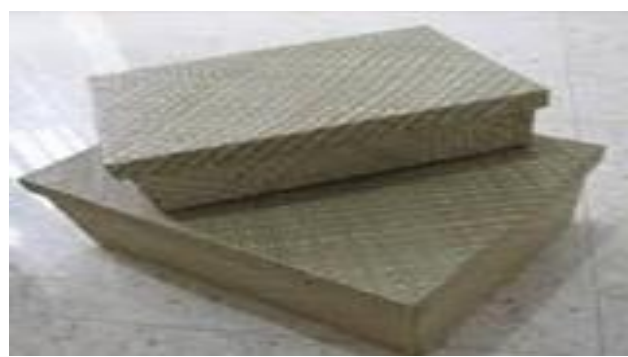

Gambar 9. Mbeka weti

\section{Te'e/ Tikar}

Tikar dianyam dari daun lontar, dianyam dua lapis digunakan untuk alas tidur sedangkan tikar besar digunakan untuk menjemur padi, jagung, wete, keö, pega, lusi dll. Pengrajin anyam tikar yang sudah dikenal oleh masyarakat umum yaitu Të Ndori dengan pinggir kain merah, Teё Reka.Të Roga biasa membuat khusus tikar jemuran.Selain untuk tempat tidur dan alas jemuran, juga digunakan untuk alas duduk bagi tamu agung atau tamu yang sangat dihormati. pada tikar, ditemukan bangun data persegi panjang. Bentuk dari tikar atau te'e dapat dilihat pada Gambar 10.

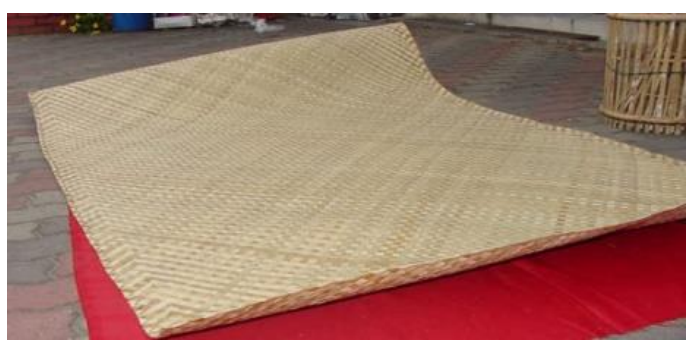

Gambar 10. Te'e/ tikar

\section{Kaja atau Gedek}

Bentuk dari kaja atau gedek dapat dilihat pada Gambar 11. Kaja atau gedek adalah anyaman yang berbahan dasar bambu untuk dijadikan dinding/plafon rumah dengan beraneka motif. pada motof kaca, di temukan bangun datar belah ketupat.

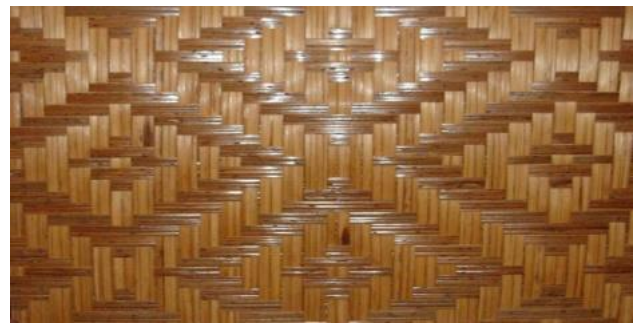

Gambar 11. Kaja/gedek

\section{Ola Bhabhe/ Alat Kipas}

Ola Bhabhe atau alat kipas merupakan alay yang terbuat dari daun kelapa atau daun lontar yang digunakan sebagai alat kipas. Pada Ola Bhabhe, dapat di temukan bangun data persegi panjang. Bentuk dari Ola Bhabhe sama seperti kipas tangan pada umumnya yang memiliki bentuk persegi atau persegi panjang. Untuk lebih jelasnya, dapat dilihat pada Gambar 12.

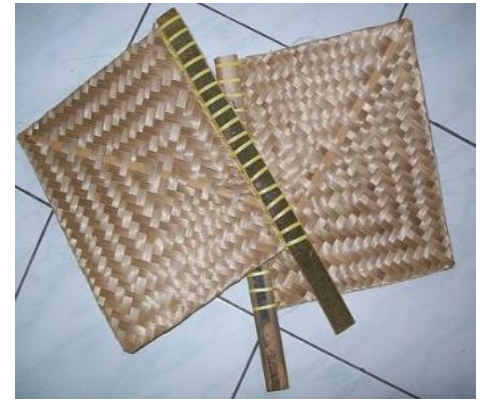

Gambar 12. Ola bhabhe

\section{Kue Cucur}

Kue cucur berbentuk bulat. Dalam bahasa matematika menyebut lingkaran. Lingkaran terdapat pada materi geometri bidang datar, selain itu juga 
dalam bahasa matematika menyatakan perbandingan, satuan berat. Kue cucur biasa di hidangkan pada acara adat, khususnya pada saat antar belis. Kue ini dijamu oleh pihakkeluarga perempuan kepada pihakkeluarga laki - laki. Yang di hidangkan bersamaan dengan kue kembang goyang, dan ditemani dengan kopi atau teh. Bentuk fisik dari kue cucur dapat dilihat pada Gambar 13.

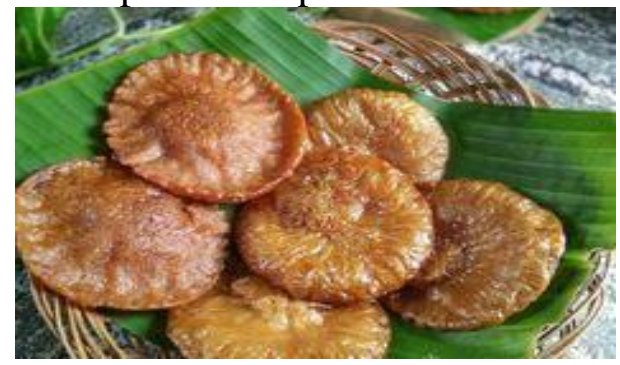

Gambar 13. Kue cucur

\section{Lamba/Gendang}

Bangun ruang tabung dapat ditemukan pada alat music tradisional Lamba/ Gendang. Dimana Lamba berbentuk menyerupai banguna tabung. Lamba / Gendang merupahkan alat music tradisional Wolotopo yang dimainkan pada saat acara adat, dan menyambut tamu kehormatan. Bentuk dari lamba atau gendang dapat dilihat pada Gambar 14.

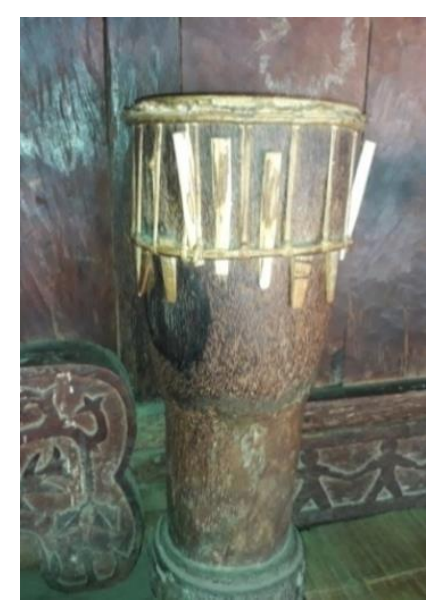

Gambar 14. Lamba/gendang

\section{Nggo atau gong}

Nggo atau gong merupakan alat musik yang terbuat dari logam dan memiliki bentuk bulat. Sama halnya dengan Lamba/Gendang, Nggo/Gong dimainkan pada saat acara adat, dan menyambut tamu kehormatan Bentuk fisik dari nggo atau gong dapat dilihat pada Gambar 15.

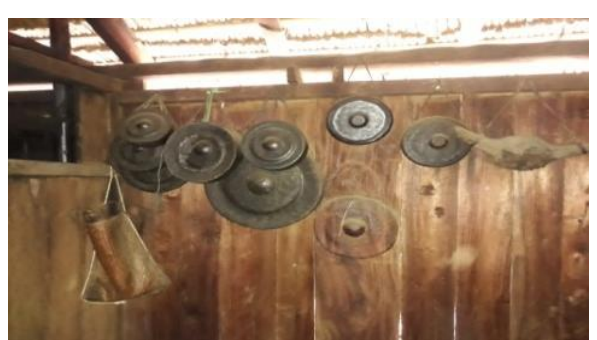

Gambar 15. Nggo atau gong

Berdasarkan data yang diperoleh, terdapat 15 jenis bagian dari kebudayaan suku Ende. Setelah diperoleh hasil, selanjutnya akan disajikan pengelompokan dari masingmasing bentuk hasil kebudayaan yang telah diidentifikasi untuk kemudian disesuaikan dengan konsep matematika yang melekat padanya. Hasil pengelompokan tersebut dapat dilihat pada Tabel 1.

Tabel 1. Hasil pengelompokan item

\begin{tabular}{|c|c|c|c|}
\hline No & $\begin{array}{c}\text { Item } \\
\text { Budaya }\end{array}$ & $\begin{array}{c}\text { Sub } \\
\text { Materi }\end{array}$ & $\begin{array}{l}\text { Materi } \\
\text { Pokok }\end{array}$ \\
\hline 1 & $\begin{array}{l}\text { Lamba/ } \\
\text { gendang } \\
\text { Feko/ suling }\end{array}$ & Tabung & $\begin{array}{l}\text { Bangun } \\
\text { ruang }\end{array}$ \\
\hline 2 & Mbeka & Balok & \\
\hline 3 & Кора & Balok & \\
\hline 4 & Ola bhabhe & $\begin{array}{l}\text { Persegi } \\
\text { panjang }\end{array}$ & \\
\hline 5 & $\begin{array}{l}\text { Nggo/gong } \\
\text { Kidhe }\end{array}$ & Lingkaran & $\begin{array}{l}\text { Bangun } \\
\text { datar }\end{array}$ \\
\hline 6 & $\begin{array}{l}\text { Lawo manu } \\
\text { Lawo soke }\end{array}$ & $\begin{array}{l}\text { Belah } \\
\text { ketupat }\end{array}$ & \\
\hline
\end{tabular}


DOI: https://doi.org/10.24127/ajpm.v10i4.4254

\begin{tabular}{llll}
\hline No & $\begin{array}{c}\text { Item } \\
\text { Budaya }\end{array}$ & $\begin{array}{c}\text { Sub } \\
\text { Materi }\end{array}$ & $\begin{array}{c}\text { Materi } \\
\text { Pokok }\end{array}$ \\
\hline 7 & Wati & $\begin{array}{l}\text { Segi } \\
\text { enam } \\
\text { beraturan }\end{array}$ & \\
8 & Kue cucur & $\begin{array}{l}\text { Bangun } \\
\text { datar }\end{array}$ \\
9 Rumah adat & $\begin{array}{l}\text { Segitiga } \\
\text { sama kaki } \\
\text { dan } \\
\text { trapesium }\end{array}$ \\
& & \\
& &
\end{tabular}

Berikut pembahasan dari hasil temuan berdasarkan masing-masing materi matematika terkait yang ditemukan.

\section{Bangun Ruang}

Pada Tabel 1 telah disebutkan bahwa item yang merepresentasikan bangun ruang mewakili sub materi tabung, balok, dan kubus. Pada objek berbentuk tabung dapat mewakili konsep tabung karena menunjukkan karakteristik tabung. Karakteristik tabung yang telah dipenuhi oleh kedua item adalah mempunyai 3 sisi, mempunyai dua rusuk, dan tidak memiliki titik sudut. Ilustrasi dari bangun tabung yang dapat direpresentasikan dengan lamba dan feko dapat dilihat pada Gambar 16.

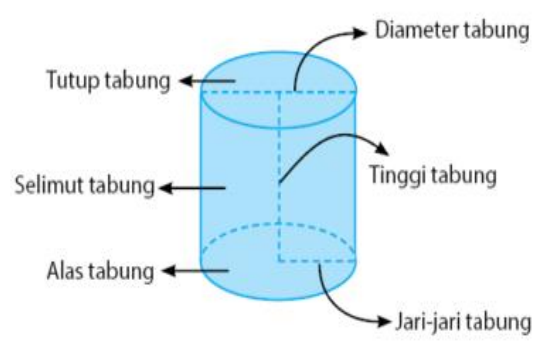

Gambar 16. Ilustrasi bangun tabung

Hasil ini menunjukkan bahwa kedua objek (lamba dan feko) dapat digunakan dalam pembelajaran geometri khususnya topik tabung.
Konsep balok yang digunakan sebagai sumber belajar matematika dapat dilihat pada Gambar 17.

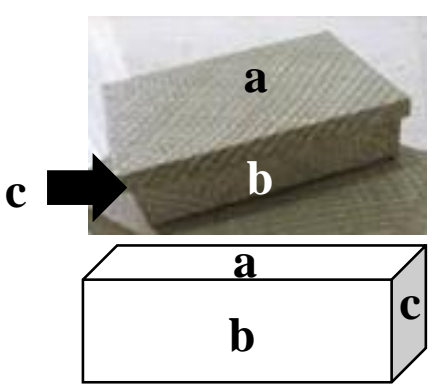

Gambar 17. Konsep balok pada objek

Berdasarkan Gambar 17, bagian a adalah bagian tutup yang kongruen dengan alas, $b$ adalah bagian depan yagn kongruen dengan bagian belakang, serta $\mathrm{c}$ adalah bagian samping balok.

Berikutnya, bentuk kubus yang diilustrasikan oleh kopa dapat dilihat pada Gambar 18.

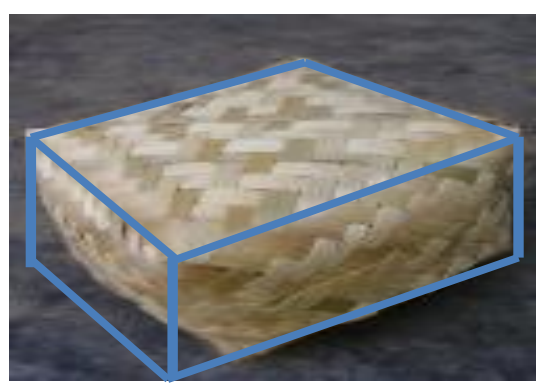

Gambar 18. Konsep Balok pada kopa

Hasil ini sejalan dengan penelitian sebelumnya bahwa suatu benda dapat digunakan dalam pembelajaran jika memuat konteks yang sesuai dengan materi yang akan disajikan atau dijelaskan (Putra et al., 2020). Penggunaan objek etnomate-matika dapat memfasilitasi peserta didik dalam memahami matematika yang bersifat abstrak dengan menggunakan objek konkret (Sutarto et al., 2021). Jika berhasil mengintegrasikan konsep geometri ke dalam kehidupan seharihari peserta didik (dalam hal ini benda di sekitarnya) maka hal ini dapat 
DOI: https://doi.org/10.24127/ajpm.v10i4.4254

membantu peningkatan pencapaian belajar peserta didik (Fouze \& Amit, 2021).

\section{Bangun Datar}

Konsep pertama adalah persegi panjang yang diilustrasikan dalam ola bhabhe atau kipas seperti yang disajikan pada Gambar 19.

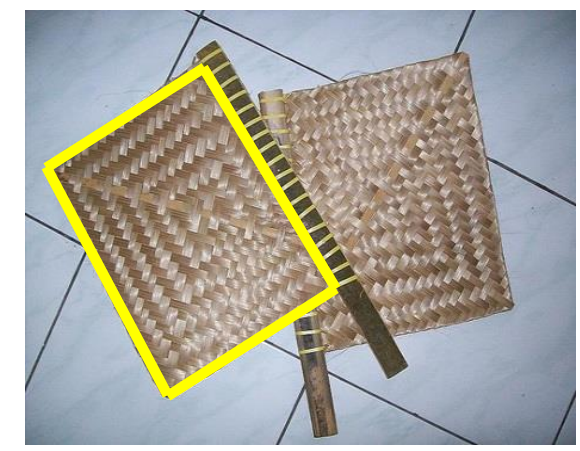

Gambar 19 Konsep persegi panjang pada ola bhabhe

Kemudian, konsep lingkaran dari objek-objek yang ada dapat dilihat pada Gambar 20.

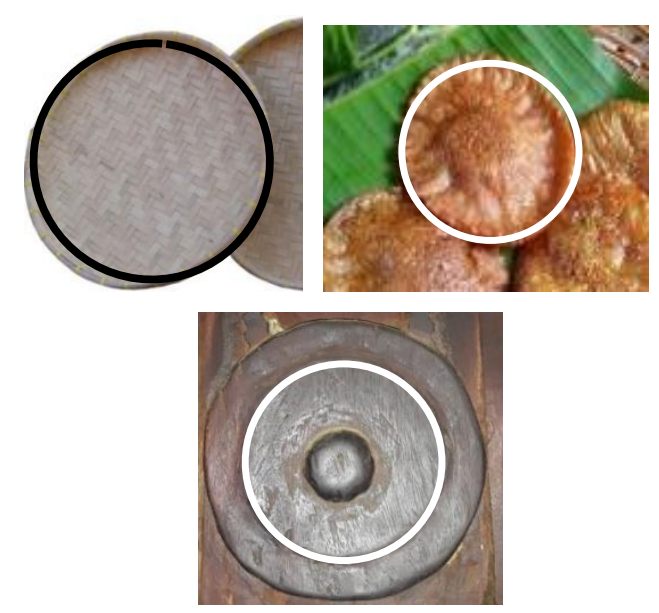

Gambar 20. Bangun lingkaran pada objek kajian

Sedangkan untuk konsep belah ketupat dapat dilihat dalam cukup banyak objek seperti yang disajikan pada pada Gambar 21.
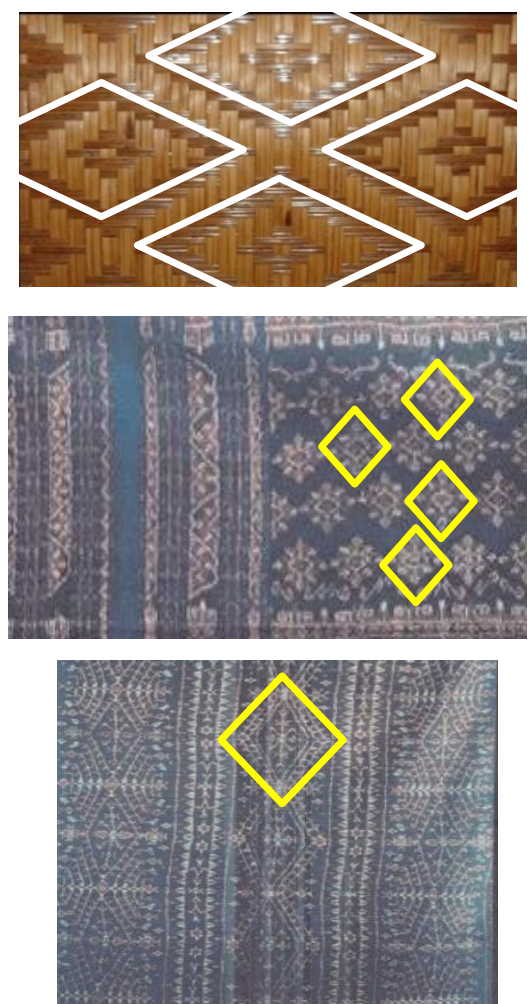

Gambar 21. Konsep belah ketupat pada objek

Konsep segitiga dan trapesium secara bersama ditunjukkan dalam 1 objek seperti pada Gambar 22.

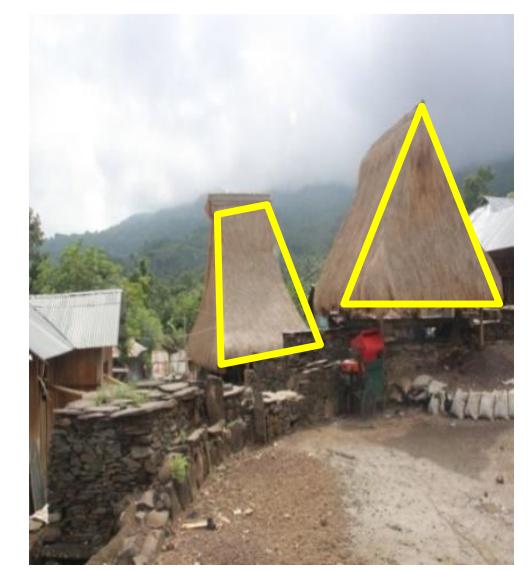

Gambar 22. Konsep segitiga dan trapesium pada objek

Terakhir, konsep segi enam beraturan ditunjukkan oleh Gambar 23. 


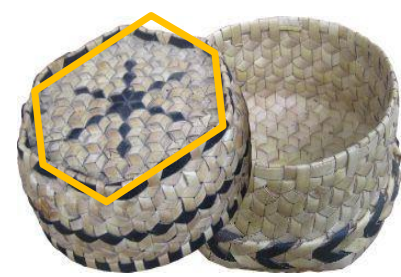

Gambar 23. Konsep segi enam pada objek

Eksplorasi serta pemanfaatan etnomatematika dalam pembelajaran telah banyak dilakukan. Konsep-konsep matematika yang dieksplorasi salah satunya adalah pada konsep bangun datar. Penelitian-penelitian yang pernah dilakukan terkait etnomatematika serta maupun pemanfaatannya dalam pembelajaran diantaranya ((Pertiwi \& Budiarto, 2020); (Hardiarti, 2017); dan (Amalia, Syamsuri, \& Ihsanudin, 2021)). Hasilnya menunjukkan bahwa penyam-paian konsep bangun datar, Bangun ruang, mengguna-kan etnomatematika memberikan inovasi dan dapat memaksimalkan pembelajaran (Hasanah et al., 2022).

Berdasarkan hasil temuan-temuan tersebut dapat digunakan sebagai media dan sumber belajar matematika oleh guru di sekolah. Selain itu juga siswa dapat mengenal, mencintai dan melestarikan budaya sekitar, sehingga budaya kita tidak ditenggelamkan oleh perubahan zaman yang semakin maju.

\section{KESIMPULAN DAN SARAN}

Berdasarkan kajian terhadap budaya Ende di peroleh beberapa unsur Etnomatematika yaitu konsep geometri bidang dan geometri ruang.

Penelitian sebenarnya masih belum mendalam, sehingga disarankan bagi peneliti lanjutan agar di gali lebih mendalam terkait sruktur dan nilai filosofis.

\section{DAFTAR PUSTAKA}

Amalia, A., Syamsuri, S., \& Ihsanudin, I. (2021). Eksplorasi Etnomatematika Batik Krakatoa Cilegon sebagai Sumber Belajar Matematika SMP. Wilangan: Jurnal Inovasi Dan ..., 2(1), 3643. Retrieved from https://jurnal.untirta.ac.id/index.ph p/wilangan/article/view/11640

Fouze, A. Q., \& Amit, M. (2021). Teaching Geometry by Integrating Ethnomathematics of Bedouin Values. Creative Education, 12, 402-421.

https://doi.org/10.4236/ce.2021.12 2029

Hardiarti, S. (2017). Etnomatematika : Aplikasi Bangun Datar. Aksioma, 8(2), 99-110.

Hasanah, D. I. I., Syarif, A., Ni'mah, L., Cahya, N. D., Mukti, S. A., \& Bambang Eko Susilo. (2022). Pendekatan Etnomatematika pada Materi Bangun Datar dengan Berbantuan Media Batik. PRISMA, Prosiding Seminar Nasional Matematika, (5), 910-913. Retrieved from https://journal.unnes.sc.id/sju/inde x.php/prisma/

Manapa, I. Y. H. (2021). Etnomatematika: Kekayaan Budaya Kabupaten Alor Sebagai Sumber Media Pembelajaran Matematika di Sekolah Dasar. Jurnal Numeracy, 8(1), 1-24.

Marina, M., \& Izzati, N. (2019). Eksplorasi Etnomatematika pada Corak Alat Musik Kesenian Marawis sebagai Sumber Belajar Matematika. Jurnal Gantang, 4(1), 39-48.

https://doi.org/10.31629/jg.v4i1.10 27 
DOI: https://doi.org/10.24127/ajpm.v10i4.4254

Nuryadi. (2020). Pendidikan Matematika Berbasis Etnomatematika di Era 4.0. Prosiding Konferensi Pendidikan Nasional, 2(1), 5-12. Yogyakarta: Universitas Mercubuana.

Pertiwi, I. J., \& Budiarto, M. T. (2020). Eksplorasi Etnomatematika Pada Gerabah Mlaten. Jurnal Cendekia : Jurnal Pendidikan Matematika, 4(2), 438-453. https://doi.org/10.31004/cendekia. v4i2.257

Putra, R. Y., Wijayanto, Z., \& Widodo, S. A. (2020). Etnomatematika: Masjid Soko Tunggal Dalam Pembelajaran Geometri 2D. Jurnal Riset Pendidikan Dan Inovasi Pembelajaran Matematika (JRPIPM), 4(1), 10-22. https://doi.org/10.26740/jrpipm.v4 n1.p10-22

Putri, L. I. (2017). Eksplorasi Etnomatematika Kesenian Rebana Sebagai Sumebr Belajar Matematika pada Jenjang MI. Jurnal Ilmiah "Pendidikan Dasar," IV(1), 21-31.

Riski, Y., Tito, V., \& Krister, P. (2020). Kajian Etnomatematika Anyaman Bambu Yogyakarta Di Desa Wisata Kerajinan Bambu Brajan Dan Implementasinya Pada Pembelajaran Topik Geometri. Seminar Nasional Pendidikan Matematika, 143-152. Retrieved from

https://conference.unikal.ac.id/inde x.php/sandika/sandika1/paper/view 1334

Rohmaini, L., Netriwati, N., Komarudin, K., Nendra, F., \& Qiftiyah, M. (2020). Pengembangan Modul Pembelajaran Matematika Berbasis Etnomatematika Berbantuan Wingeom Berdasarkan Langkah
Borg and Gall. Teorema: Teori Dan Riset Matematika, 5(2), 176186. https://doi.org/10.25157/teorema.v 5i2.3649

Rupa, J. N., \& Ri'a, M. P. P. (2021). Makna Simbolik Motif Khas Sarung Ende Lio. Jurnal KIBASP (Kajian Bahasa, Sastra, Dan Pengajaran), 4(2), 251-262.

Sutarto, S., Ahyansyah, A., Mawaddah, S., \& Hastuti, I. D. (2021). Etnomatematika: Eksplorasi Kebudayaan Mbojo Sebagai Sumber Belajar Matematika. JP2M (Jurnal Pendidikan Dan Pembelajaran Matematika), 7(1), 33-42. https://doi.org/10.29100/jp2m.v7i1 .2097

Ubayanti, C. S., Lumbantobing, H., \& Manurung, M. M. H. (2016). Eksplorasi Etnomatematika Pada Sero (Set-Net) : Budaya Masyarakat Kokas Fakfak Papua Barat. Jurnal Ilmiah Matematika Dan Pembelajarannya, 1(1), 1221. 